\title{
BIOLOGICAL ACTIVITIES OF PHTHALOCYANINES-X. SYNTHESES AND ANALYSES OF SULFONATED PHTHALOCYANINES
}

\author{
Hasrat Ali, Réjean langlois, J. Richard Wagner, Nicole Brasseur, Benoit Paquette \\ and JOHAN E. VAN LIER* \\ MRC Group in the Radiation Sciences, Faculty of Medicine, University of Sherbrooke, Sherbrooke, \\ Québec, Canada JlH 5N4
}

(Received 19 August 1987; accepted 2 November 1987)

\begin{abstract}
Synthetic methods to obtain selectively sulfonated metallo phthalocyanines are compared. Both condensation and direct sulfonation procedures lead to mixtures of mono- to tetrasulfonated products which are resolved by reverse phase liquid chromatography in buffered aqueous-methanol. The proportion of sulfonated derivatives is examined as a function of the starting reagents in the case of the condensation method, and as a function of the temperature and reaction time in the case of the direct sulfonation procedure. The number of sulfonate groups per phthalocyanine molecule is determined by oxidative degradation of the phthalocyanine ring followed by quantitative chromatographic analysis of the sulfophthalamide and phthalamide fragments.
\end{abstract}

\section{INTRODUCTION}

Phthalocyanines $(\mathrm{PC}) \dagger$ and their water soluble sulfonated derivatives (SPC) (Fig. 1) have received increasing attention as sensitizers for photodynamic therapy of cancer [for recent reviews, see Spikes (1986), Ben-Hur (1987), van Lier et al. (1988)]. The degree of sulfonation affects the tendency of the SPC to aggregate, and thus changes their ability to generate ${ }^{1} \mathrm{O}_{2}$ (Wagner et al., 1987), and to be transported through cell membranes which are important factors of their photocytotoxicity (Brasseur et al., 1987a). Accordingly, comparative studies of metallo-SPC demand well characterized dye preparations. We describe here a simple procedure for the analysis of the average number of sulfonate groups per PC molecule in SPC preparations (S/PC ratio) as well as analytical and preparative chromatographic methods for separating SPC. The principal synthetic procedures for metallo-SPC are investigated with respect to the complexity and the degree of sulfonation of the product mixtures.

\section{MATERIALS AND METHODS}

Gallium metal, phthalic acid, 4-sulfophthalic acid, phthalamide. 1,2-dicyanobenzene and phthalic anhydride were purchased from Aldrich. $\mathrm{Zn}-\mathrm{PC}$ and $\mathrm{AlCl}-\mathrm{PC}$ were purchased from Eastman Kodak. Fuming sulfuric acid $\left(30 \%\right.$ free $\left.\mathrm{SO}_{3}\right)$ and HPLC grade solvents were obtained from Fisher Scientific. Triply distilled water was used throughout this work. The Carbon-13 Nuclear Magnetic Resonance ( ${ }^{13} \mathrm{C}$. NMR) spectra were recorded on a Bruker WM 250 apparatus with $\mathrm{D}_{2} \mathrm{O}$ or $\mathrm{D}_{2} \mathrm{SO}_{4}$ as the solvent. Chemical shifts are reported in ppm relative to TMS. Ultraviolet-visible absorption spectra were recorded on a

*To whom correspondence should be addressed.

$\dagger$ Abbreviations: DSPC, diSPC; MSPC, monoSPC; PC, phthalocyanine; SPC, sulfophthalocyanine; TFA, trifluoroacetic acid.
Varian 2000 spectrophotometer. Combustion analyses were performed by Guelph Chemical Laboratories, Guelph, Ont. Canada.

Syntheses of metallo sulfophthalocyanines. The syntheses of $\mathrm{GaCl}-\mathrm{SPC}$, sulfonated to different degrees, is described in detail as an example. Other metallo-SPC, including $\mathrm{AlCl}$ - and $\mathrm{Zn}-\mathrm{SPC}$, were prepared in similar manners.

Tetrasodium salt of chlorogallium 4,4',5",5"'-tetrasulfophthalocyanine (GaCl-TSPC) by the condensation method. The procedure was adapted from Weber and Bush (1965). It has recently been shown by Gaspard and Maillard (1987) that the substituents of tetrasubstituted metallo-PC, obtained from the 4-substituted phthalo monomer, are oriented on the $4,4^{\prime}, 5^{\prime \prime}, 5^{\prime \prime \prime}$-positions during the formation of the macrocycle, resulting in the formation of only one out of four possible constitutional isomers. $\mathrm{GaCl}_{3}$ was prepared by reaction of metallic gallium with concentrated $\mathrm{HCl}$. The monosodium salt of 4-sulfophthalic acid $(4.3 \mathrm{~g}, 16.2 \mathrm{mmol}), \mathrm{NH}_{4} \mathrm{Cl}(470 \mathrm{mg}, 90 \mathrm{mmol})$, urea $(5.8 \mathrm{~g}, 970 \mathrm{mmol})$, ammonium molybdate $(68 \mathrm{mg}, 0.06$ $\mathrm{mmol}$ ) and $\mathrm{GaCl}_{3}(875 \mathrm{mg}, 0.5 \mathrm{mmol})$ were pulverized to a homogeneous powder. The material was heated to $180^{\circ} \mathrm{C}$ at which point urea decomposes to yield $\mathrm{NH}_{3}$. After 30 min the temperature was raised to $200^{\circ} \mathrm{C}$ for $4 \mathrm{~h}$ in order to complete the condensation reaction. The solid cake was dispersed in boiling $1 \mathrm{~N} \mathrm{HCl}$ saturated with $\mathrm{NaCl}(500$ $\mathrm{m} \ell$ ), cooled to room temperature and the precipitate was collected and redissolved in $0.1 \mathrm{~N} \mathrm{NaOH}(200 \mathrm{~m} \ell)$. The solution was heated to $80^{\circ} \mathrm{C}$, filtered to remove insoluble impurities, neutralized with $1 \mathrm{~N} \mathrm{HCl}$ and evaporated on a vacuum to yield a green solid. Part of the crude material (100 mg) was purified by preparative reverse phase HPLC in water to remove salt, followed by $50 \% \mathrm{MeOH}$ in water to yield $30 \mathrm{mg}$ of the $\mathrm{GaCl}$-TSPC. ${ }^{13} \mathrm{C}$ NMR data are reported in Table 1 . UV-vis $\left(\mathrm{MeOH}\right.$, monomeric) $\lambda_{\max }(\epsilon$ $\left.10^{4} \mathrm{~cm}^{-1} M^{-1}\right): 674(22), 609(2.9), 342(14.1) \mathrm{nm}$. Anal. Calc. for $\mathrm{C}_{32} \mathrm{H}_{12} \mathrm{~N}_{8} \mathrm{~S}_{4} \mathrm{O}_{12} \mathrm{ClGa}$. $9 \mathrm{H}_{2} \mathrm{O}$ (mol. wt. 1188): C, 32.33; H, 2.54; N, 9.43. Found C, 32.7; H, 2.21; N, 9.75.

Mono- to trisulfonated chlorogallium phthalocyanines ( $\mathrm{GaCl}-\mathrm{SPC}$ ) by the condensation method. Mixtures of mono- to tetrasulfonated $\mathrm{GaCl}-\mathrm{SPC}$ were obtained in a similar manner as described for the GaCl-TSPC by substituting the sulfophthalic acid with mixtures of various ratios of phthalic acid, or anhydride, and sulfophthalic acid. The homogeneous mono- to trisulfonated complexes were obtained from preparative reverse phase medium pressure 
Table $1 .{ }^{13} \mathrm{C}-\mathrm{NMR}$ of phthalocyanines

\begin{tabular}{|c|c|}
\hline $\mathrm{PC}$ & Chemical shifts in ppm (carbon number) ${ }^{*}$ \\
\hline$Z_{n}-P C$ & $133.76\left(C_{1.8}\right), 127.12\left(C_{2.7}, 124.98\left(C_{3.4 .5 .6}\right)\right.$ \\
\hline $\mathrm{AlCl}-\mathrm{PC}$ & $149.12\left(C_{1.8}\right), 135.20\left(C_{2,7}\right), 126.10\left(C_{3.4 .5 .6}\right)$ \\
\hline $\mathrm{GaCl}-\mathrm{PC}$ & $\begin{array}{l}149.67\left(\mathrm{C}_{1.8}\right), 135.01\left(\mathrm{C}_{2.7}\right), 126.36\left(\mathrm{C}_{3,6}\right) \\
\text { and } 125.85\left(\mathrm{C}_{4.5}\right)\end{array}$ \\
\hline GaCl-TSPC & $\begin{array}{l}149.4\left(C_{1.8}\right), 146.1\left(C_{4}\right), 132.4\left(C_{7}\right), 130.9 \\
\left(C_{2}\right), 129.2\left(C_{6}\right), 125.5\left(C_{3}\right) \text { and } 122.8\left(C_{5}\right)\end{array}$ \\
\hline GaCl-TSPCt & $\begin{array}{l}154.3\left(\mathrm{C}_{1.8}\right), 148.3\left(\mathrm{C}_{4}\right), 138.3\left(\mathrm{C}_{7}\right), 137.8 \\
\left(\mathrm{C}_{2}\right), \quad 131.4\left(\mathrm{C}_{6}-\mathrm{H}\right),+127.2\left(\mathrm{C}_{3}-\mathrm{H}\right) \neq \text { and } \\
123.2\left(\mathrm{C}_{5}-\mathrm{H}\right) \neq\end{array}$ \\
\hline
\end{tabular}

${ }^{*}$ Spectra taken in $\mathrm{D}_{2} \mathrm{SO}_{4}$, except for $b$. Carbon numbers refer to Fig. 1 and the structure on Fig. 4 and are tentatively assigned (see discussion in text). †Taken in $\mathrm{D}_{2} \mathrm{O}$. $\ddagger$ Reversed signals, indicative of methine carbons.

chromatography and HPLC.

Mono- to tetrasulfonated chlorogallium phthalocyanines ( $\mathrm{GaCl}-S \mathrm{PC}$ ) by the sulfonation method. The sulfonation procedure was adapted from Linstead and Weiss (1950). Chlorogallium phthalocyanine (GaCl-PC; $308 \mathrm{mg} ; 0.5$ $\mathrm{mmol}$ ), prepared via the condensation method, was dissolved in $15 \mathrm{~m} \ell$ oleum (fuming $\mathrm{H}_{2} \mathrm{SO}_{4}$ containing $30 \%$ free $\mathrm{SO}_{3}$ ) and heated at $75^{\circ} \mathrm{C}$ with stirring. The mixture was kept at this temperature for $1-4 \mathrm{~h}$ depending on the degree of sulfonation required, whereafter it was poured onto crushed ice. The resulting dark green precipitate was filtered and washed with $1 N \mathrm{HCl}(10 \mathrm{~m} \ell)$, redissolved in $1 \mathrm{~N} \mathrm{NaOH}(20 \mathrm{~m} \ell)$ and filtered in order to remove waterinsoluble impurities including nonsulfonated PC. The filtrate was neutralized with $1 \mathrm{~N} \mathrm{HCl}$, analyzed by HPLC, concentrated under vacuum and stored at $0^{\circ} \mathrm{C}$ pending chromatographic purification.

Preparative medium pressure chromatography. Sulfonated metallo-PC were purified on a $30 \mathrm{~cm}$ long by $2 \mathrm{~cm}$ ID glass column packed with $\mathrm{C}-18$ reverse phase, particle size 25-40 $\mu \mathrm{m}$ (Macherey-Nagel, Düren, Germany) using a linear gradient (140 min) from 0 to $95 \% \mathrm{MeOH}$ in 10 $\mathrm{m} M$ sodium phosphate buffer, $\mathrm{pH} 5$, at a flow rate of 2 $\mathrm{m} \ell \min ^{-1}$. A concentrated dye solution $(30 \mathrm{mg})$ was loaded on to the column with a FMI model RP-SY pump. Eluting SPC were detected at 650 or $680 \mathrm{~nm}$ and desalted by rechromatography on the same column in water $(100$ $\mathrm{m} \ell$ ). The mixed mono- to tetrasulfonated dyes were eluted with $\mathrm{MeOH}(25-75 \%)$ in water.

Reverse phase HPLC. Metallo-SPC sulfonated to different degrees and their constitutional isomers were separated on a $25 \mathrm{~cm}$ long by $0.94 \mathrm{~cm}$ ID semi-preparative reverse phase column packed with ODS-2 spherisorb, 5 $\mu \mathrm{m}$ (CSC, Montreal), operated at $2 \mathrm{~m} \ell \mathrm{min}^{-1}$ with a linear gradient (55 min) from 0 to $95 \% \mathrm{MeOH}$ in $10 \mathrm{~m} M$ sodium phosphate buffer, $\mathrm{pH} 5$. SPC were detected by their absorption at 650 or $680 \mathrm{~nm}$. This system was used for both analytical and preparative purposes. Retention times of various metallo-SPC were only slightly affected by the nature of the central metal ion and varied from $20-25 \mathrm{~min}$ for the TSPC, $25-35 \mathrm{~min}$ for the triSPC, 35-55 for the DSPC, and 55-65 min for the MSPC metallo complexes. The resolution between the various isomers and differently sulfonated SPC in this system depends on the synthetic procedure and the nature of the central metal ion. For example, near-baseline separations between the constitutional isomers of the disulfonated dye were achieved (Fig. 2A) for GaCI-SPC prepared by the condensation procedure.

Degree of sulfonation. The average number of sulfonate groups per SPC molecule (S/PC ratio) of SPC preparations was determined by a simple oxidative degradation procedure followed by HPLC in order to quantify the corresponding sulfophthalimide and phthalimide products. Briefly, $1 \mathrm{mg}$ of the sulfonated dye is dissolved in a minimal volume of concentrated $\mathrm{HNO}_{3}$ and the solution is heated to $50^{\circ} \mathrm{C}$ until the characteristic green SPC color disappears (1-5 min). The solution is neutralized with 1 $N \mathrm{NaOH}$ and analyzed on a reverse phase HPLC column (see above). The solvent program consists of a $5 \mathrm{~min}$ isocratic elution with $0.1 \%$ trifluoroacetic acid (TFA) in water followed by a $30 \mathrm{~min}$ linear gradient from this

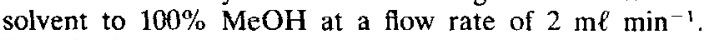
Phthalimide products are well separated in this system and detected by their absorption at $215 \mathrm{~nm}$ (Fig. 2). Retention times of the three possible products are, 3 -sulfophthalimide $15 \mathrm{~min}, 4$-sulfophthalimide $16 \mathrm{~min}$ and phthalimide 28 min. These products were quantified by manual integration of the peak surface.

\section{RESULTS AND DISCUSSION}

The synthesis of sulfonated phthalocyanines is easy, however, the resulting mixtures of more or less sulfonated products and constitutional isomers are difficult to separate. We initially examined the feasibility of separating metallo-SPC mixtures by electrophoresis, ion exchange, Sephadex exclusion, silica gel column and thin layer chromatography (Rousseau et al., 1983) and ion-pair reverse phase HPLC (Gloor and Johnson, 1977; Oppenheimer, 1981), but found that conventional reverse phase HPLC, using mixtures of phosphate buffered water and $\mathrm{MeOH}$, resulted in the best resolution. Furthermore, in the case of preparative separations, phosphate buffer is easier to remove from the product than are ion-pairing agents. A comparison of the analysis of $\mathrm{GaCl}-\mathrm{SPC}$ mixtures obtained either from condensation or from sulfonation methods is presented in Fig. 2. In the case of the condensation method when starting with various mixtures of sulfophthalic-phthalic acid, HPLC analysis gave baseline separation of individual components in each of the four groups of peaks observed. All of these peaks showed the characteristic UV-vis absorption

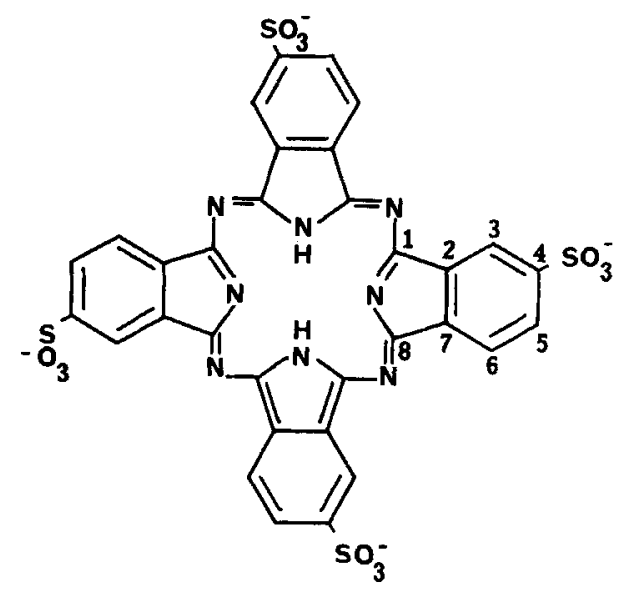

Figure 1. Structure of one of the possible isomers of tetrasulfophthalocyanine (TSPC). 
spectrum of the $\mathrm{GaCl}-\mathrm{PC}$ macrocycle $\left(\lambda_{\max } 674 \mathrm{~nm}\right.$ in $\mathrm{MeOH}$ ), with a constant UV/vis absorbance ratio. The degree of sulfonation ( $\mathrm{S} / \mathrm{PC}$ ratio) of the four major HPLC fractions (Fig. 2) was determined by the degradation assay. In the order of their increasing retention times, fractions were identified as tetra- to monosulfonated $\mathrm{GaCl}-\mathrm{SPC}$. The di- and trisulfonated regions are comprised of several peaks representing constitutional isomers. The four disulfonated $\mathrm{GaCl}$-SPC isomers (Fig. 2A) were separately tested for their in vitro photosensitizing activities (Brasseur et al., 1987b). Marked differences were observed between the biological activities which correlate well with differences in hydrophobicity and cell penetrating properties of the isomeric dyes. In accordance with the mobilities of isomeric disulfonated tetraphenyl porphyrins (Kessel et al., 1987), we assign the isomer with sulfonate groups in opposite phthalic subunits of the PC molecule as the most hydrophilic $\left(R_{\mathrm{t}}=40 \mathrm{~min}\right)$ whereas the one with adjacent groups as the most hydrophobic $\left(R_{\mathrm{t}}=48\right.$ min) (Fig. 2). The amphiphilic nature of the latter isomer may well explain its marked cell membrane penetrating properties and high cellular phototoxicity.

Direct sulfonation of GaCl-PC gave a more complex HPLC elution pattern (Fig. 2B) with several peaks at $215 \mathrm{~nm}$ lacking the characteristic phthalocyanine UV-vis absorption. These peaks are most likely degradation products formed as a result of the

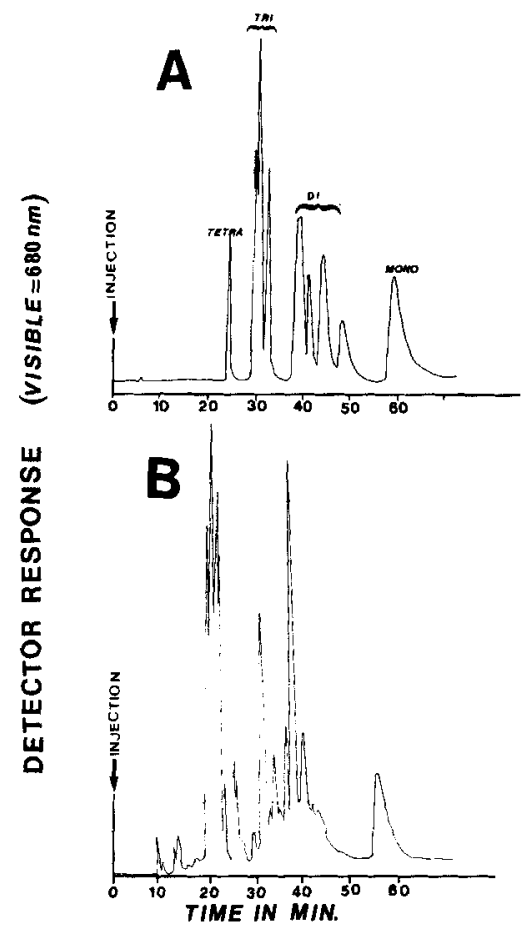

Figure 2. HPLC analysis of GaCl-SPC obtained by the condensation of phthalic and 4-sulfophthalic acid (1:1) with $\mathrm{GaCl}_{3}(\mathrm{~A})$, and $\mathrm{GaCl}$-SPC obtained by direct sulfonation of $\mathrm{GaCl}-\mathrm{PC}$ in oleum for $4 \mathrm{~h}$ at $75^{\circ} \mathrm{C}$ (B).

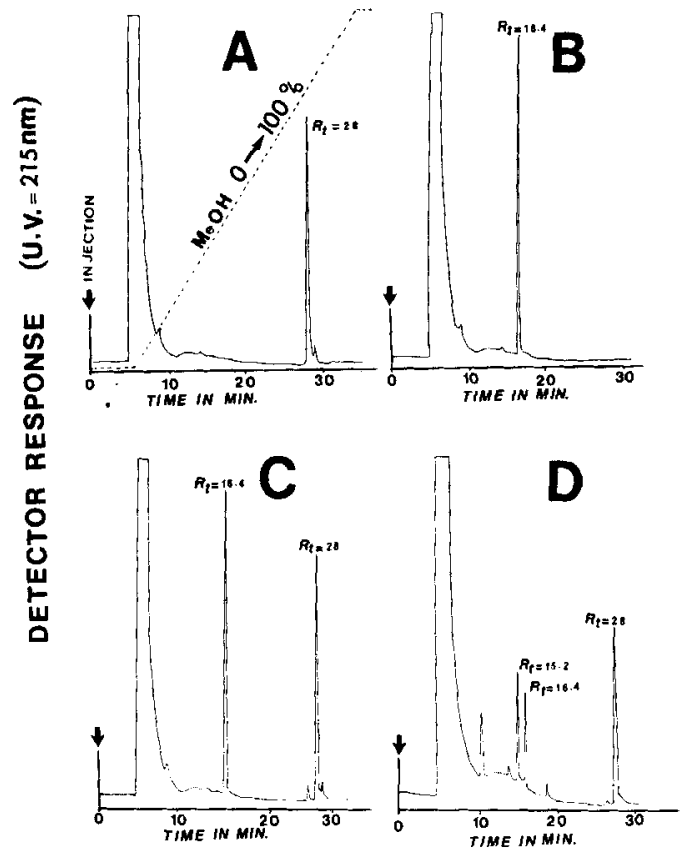

Figure 3. HPLC analysis of phthalimides for the S/PC ratio assay. (A) authentic phthalimide, (B) authentic 4 sulfophthalimide, (C) mixture of phthalimide and 4-sulfophthalimide $(1: 1)$ obtained from $\mathrm{HNO}_{3}$ degradation of GaCl-DSPC prepared via the condensation method and (D) mixture of phthalimide, 4-sulfophthalimide and 3 sulfophthalimide $(2: 1: 1)$ obtained from $\mathrm{HNO}_{3}$ degradation of GaCl-DSPC prepared via the sulfonation method.

extreme conditions required for sulfonation. Direct sulfonation results in substitution at both the 3-and 4-positions of the phthalic subunits, further contributing to the high complexity of the product mixture. The degradation assay of individual HPLC fractions indicates the presence of equal amounts of 3- and 4-sulfophthalimide (Fig. 3). This contrasts with SPC obtained by way of the condensation method where the phthalic subunits are only substituted at the 4-position (Fig. 3).

The ${ }^{13} \mathrm{C}$ proton decoupled NMR spectra of $\mathrm{Zn}$ and $\mathrm{AlCl}-\mathrm{PC}$ display three sharp signals in $\mathrm{D}_{2} \mathrm{SO}_{4}$. As for porphyrins, the carbons closer to the PC center are shifted to higher ppm because of deshielding effects of the macrocycle ring current (Abraham et al., 1982), thereby, these signals can be assigned as the $C_{1}$ and $C_{8}$ pair furthest downfield followed by $C_{2}$ and $C_{7}$ and then four equivalent benzyl carbons which are least affected by the $\mathrm{PC}$ ring (Fig. 4 and Table 1). Interestingly, the benzyl carbons of $\mathrm{GaCl}-\mathrm{PC}$ are split into two signals suggesting ring distortion for this metallo complex. This may be caused by an out-of-plane position of the central metal ion, which can be expected more pronounced in $\mathrm{GaCl}-\mathrm{PC}$ as compared to the analogous complex with the smaller Al ion. The spectra of $\mathrm{GaCl}$-TSPC shows seven carbon signals in $\mathrm{D}_{2} \mathrm{SO}_{4}$ as well as in $\mathrm{D}_{2} \mathrm{O}$. Concentration effects leading to 

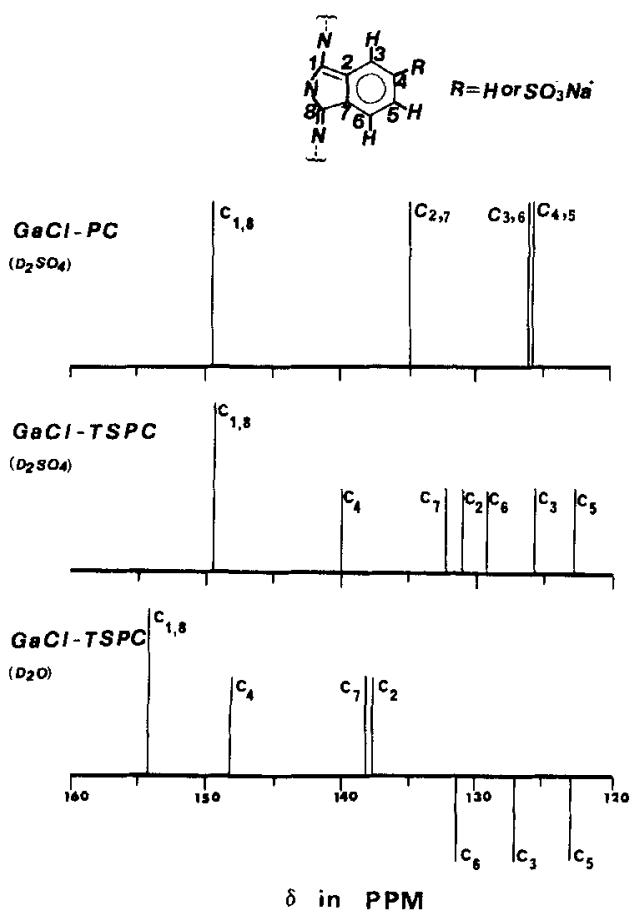

Figure $4 .{ }^{13} \mathrm{C}$ NMR bar plot of signals from $\mathrm{GaCl}-\mathrm{PC}$ and $\mathrm{GaCl}$-TSPC taken in $\mathrm{D}_{2} \mathrm{SO}_{4}$ and $\mathrm{D}_{2} \mathrm{O}$. Chemical shifts are in $\mathrm{ppm}$ relative to TMS.

intermolecular ring current shielding appear to be responsible for the increased chemical shifts in $\mathrm{D}_{2} \mathrm{O}$, since the $\mathrm{GaCl}$-TSPC solution ( $40 \mathrm{mg} / 2 \mathrm{~m} \ell$ ) is expected to be aggregated. The carbon signals were further characterized by employing $\mathrm{J}$-resolved spin echo which permits separation of the quaternary from methine carbons. Two of these carbons, $C_{1}$ and $\mathrm{C}_{2}$ can be assigned as a single fairly broad multiplet at about $154 \mathrm{ppm}$ (in $\mathrm{D}_{2} \mathrm{O}$ ). Keeping these results in mind, then, the complete assignment was further aided by comparison with benzene sulfonic acid. The shift of sulfonated substituted aromatic carbons is about 16 ppm which is consistent with a 20 ppm shift of $C_{4}$ (Breitmaier et al., 1979). Benzene sulfonic acid also shows the bigger chemical shift at the para position $(+4.8 \mathrm{ppm})$ followed by the meta positions $(+2.3 \mathrm{ppm})$ while the ortho carbons are shifted slightly upfield ( $-1.2 \mathrm{ppm}$ ) with respect to benzene. Therefore, we expect $C_{7}$ to be at higher ppm than $\mathrm{C}_{2}$ and for identical meta positions, $C_{3}$ would likely appear at higher ppm as compared to $\mathrm{C}_{5}$ because $\mathrm{C}_{3}$ is closer to the PC ring.

The effect of the percentage of sulfophthalic vs phthalic acid and the nature of other reactants on the composition of the condensation reaction products is summarized in Table 2. It may be seen from this table that the highest percentage of the most biologically active mono- and disulfonated $\mathrm{GaCl}$ SPC (Brasseur et al., 1987) are obtained with 50\% 4-sulfophthalic acid. Phthalic acid can be replaced with a number of other reactants, including 1,2dicyanobenzene, phthalic anhydride and phthalamide. Condensation of these compounds in the presence of sulfophthalic acid always results in similar ratios between the differently sulfonated SPC products. Likewise, the nature of the metal ion has little effect on the product distribution pattern (Table 2). In contrast, with the direct sulfonation of the metallo-PC, the nature of the central metal ion strongly affects the course of the reaction (Table 3). Thus, with $\mathrm{Zn}-\mathrm{PC}$ as a substrate, good yields of a relative clean mixture of mono- and disulfonated $\mathrm{Zn}-\mathrm{SPC}$ is obtained after $30 \mathrm{~min}$ at $50^{\circ} \mathrm{C}$, whereas similar yields of mono- and disulfonated product with the $\mathrm{GaCl}$ -

Table 2. Relative yields of mono- to tetrasulfonated metallo SPC obtained via the condensation method

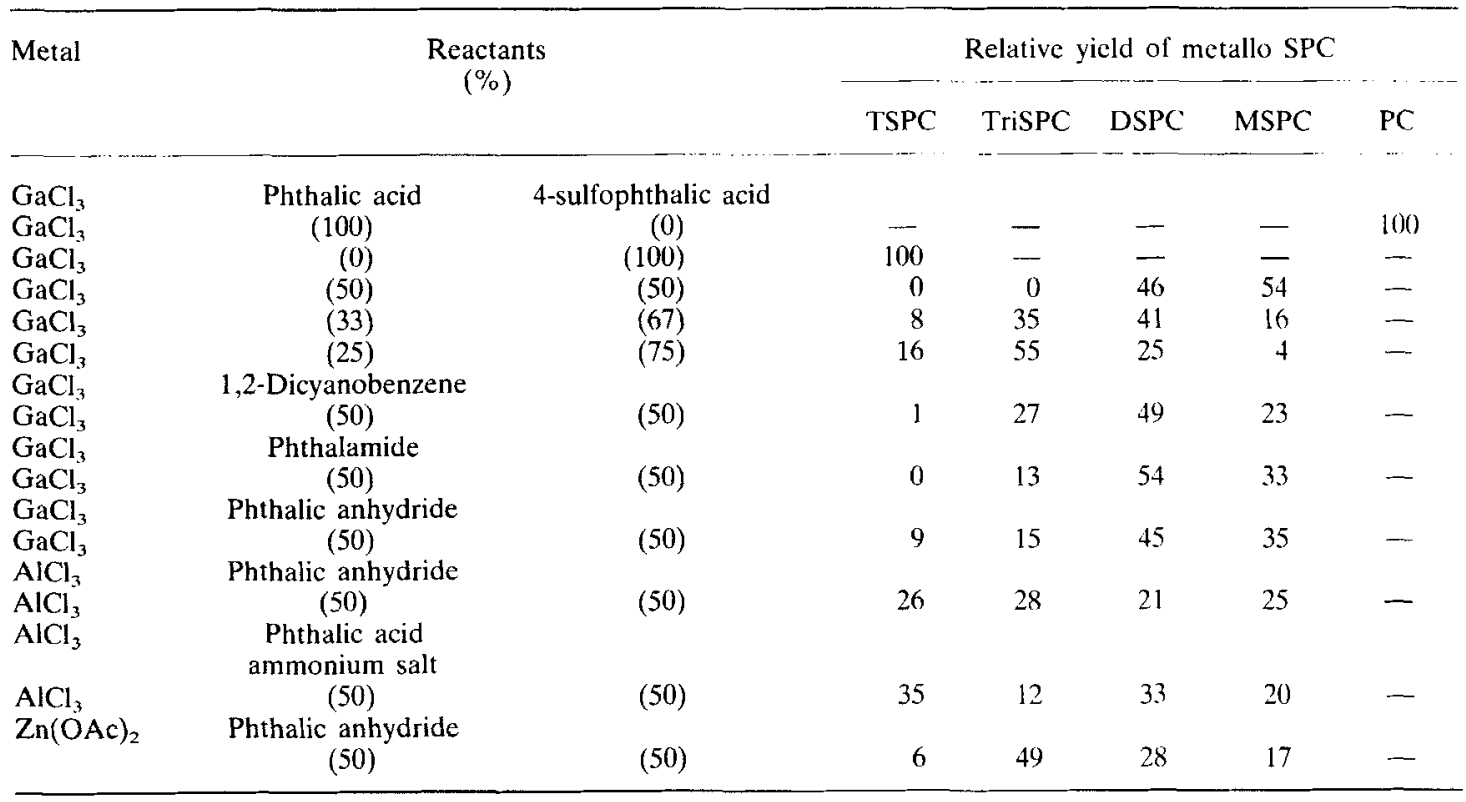


Table 3. Relative yields of mono- to tetrasulfonated metallo SPC obtained via the sulfonation method

\begin{tabular}{|c|c|c|c|c|c|c|}
\hline \multirow[t]{2}{*}{ Substrate } & \multirow{2}{*}{$\begin{array}{l}\text { Temp. } \\
\left({ }^{\circ} \mathrm{C}\right)\end{array}$} & \multirow{2}{*}{$\begin{array}{c}\text { Time } \\
\text { (h) }\end{array}$} & \multicolumn{4}{|c|}{ Relative yield of metallo SPC } \\
\hline & & & TSPC & TriSPC & $\mathrm{DSPC}$ & MSPC \\
\hline $\mathrm{GaCl}-\mathrm{PC}$ & 50 & 8 & 4 & 8 & 16 & 72 \\
\hline $\mathrm{GaCl}-\mathrm{PC}$ & 75 & 1 & 2 & 6 & 10 & 82 \\
\hline $\mathrm{GaCl}-\mathrm{PC}$ & 75 & 2 & 11 & 12 & 27 & 50 \\
\hline $\mathrm{GaCl}-\mathrm{PC}$ & 75 & 4 & 44 & 16 & 31 & 9 \\
\hline $\mathrm{GaCl}-\mathrm{PC}$ & 85 & 6 & $>95$ & - & - & - \\
\hline $\mathrm{Zn}-\mathrm{PC}$ & 50 & 0.5 & - & 2 & 48 & 50 \\
\hline $\mathrm{Zn}-\mathrm{PC}$ & 75 & 1 & - & 29 & 71 & - \\
\hline $\mathrm{Zn}-\mathrm{PC}$ & 75 & 2 & - & 62 & 38 & - \\
\hline $\mathrm{Zn}-\mathrm{PC}$ & 75 & 4 & 9 & 77 & 14 & - \\
\hline $\mathrm{Zn}-\mathrm{PC}$ & 85 & 6 & $>90$ & - & - & - \\
\hline AlCl-PC & 75 & 1 & 0 & 3 & 7 & 90 \\
\hline AlCl-PC & 75 & 2 & 4 & 9 & 25 & 62 \\
\hline $\mathrm{AlCl}-\mathrm{PC}$ & 75 & 4 & 14 & 20 & 30 & 36 \\
\hline
\end{tabular}

or $\mathrm{AlCl}-\mathrm{PC}$ require substantially longer reaction times and higher temperatures (Table 3). Although the condensation method gives less complex mixtures and is more reproducible, comparison of the two methods (Tables 2 and 3) shows that if monoand disulfonated products are required, direct sulfonation is the preferred procedure.

In conclusion, phthalocyanines and their sulfonated derivatives are readily prepared but often require extensive chromatography to ensure homogeneity. We have presented chromatographic procedures to analyse the composition, including the degree of sulfonation, of phthalocyanine preparations. In view of the extreme differences in biological activities as to the degree of sulfonation and type of isomers, it is important to report such characteristics of dye preparations used in photodynamic protocols.

Acknowledgements-Generous financial support for this work was provided by the Medical Research Council of Canada and the National Cancer Institute of Canada.

\section{REFERENCES}

Abraham, R. J., K. M. Smith, D. A. Goff and J.-J. Lai (1982) NMR spectra of porphyrins. 18. A ring-current model for chlorophyll derivatives. J. Am. Chem. Soc. 104, 4332-4337.

Ben-Hur, E. (1987) Photochemistry and photobiology of phthalocyanines: new sensitizers for photodynamic therapy of cancer. In From Photophysics to Photobiology (Edited by A. Favre, R. Tyrrell and J. Cadet), pp. 407-420. Elsevier, New York.

Brasseur, N., H. Ali, R. Langlois and J. E. van Lier (1987b) Biological activities of phthalocyanines-VII Photoinactivation of V-79 Chinese hamster cells by selectively sulfonated gallium phthalocyanines. Photochem. Photobiol. 46, 739-744.

Brasseur, N., H. Ali, R. Langlois, J. R. Wagner, J. Rous- seau and J. E. van Lier (1987a) Biological activities of phthalocyanines-V. Photodynamic therapy of EMT6 mammary tumors in mice with sulfonated phthalocyanines. Photochem. Photobiol. 45, 581-586.

Breitmaier, E., G. Haas and W. Voelter (1979) Allas of Carbon-13 NMR data, Vol. 2, Compound No. 1971. Heyden, New York.

Gaspard, S. and Ph. Maillard (1987) Structure des phthalocyanines tetratertio-butyles: Mécanisme de la synthèse. Tetrahedron 43, 1083-1090.

Gloor, R. and E. L. Johnson (1977) Practical aspects of reverse phase ion-pair chromatography. J. Chromatogr. Sci. 15, 413-423.

Linstead, R. P. and F. T. Weiss (1950) Phthalocyanines and related compounds. Part XX. Further investigations on tetrabenzoporphin and allied substances. J. Chem. Soc. 2975-2981.

Oppenheimer, L. E. (1981) Ion-pair chromatography of sulfonated copper phthalocyanine. J. Chromatogr. Sci. 19. 266-269.

Rousseau, J., D. Autenrieth and J. E. van Lier (1983) Synthesis, tissue distribution and tumor uptake of "Tctetrasulfophthalocyanine. Int. J. Appl. Radiat. Isot. 34, 571-579.

Spikes, J. E. (1986) Yearly review: Phthalocyanines as photosensitizers in biological systems and for the photodynamic therapy of tumors. Photochem. Photobiol. 43, 691-699.

van Lier, J. E., N. Brasseur, B. Paquette, J. R. Wagner, H. Ali, R. Langlois and J. Rousseau (1988) Phthalocyanines as sensitizers for photodynamic therapy of cancer, In Photosensitization: Molecular and Medical Aspects (Edited by G. Moreno, R. H. Pottier and T. $G$. Truscott). Springer-Verlag, Berlin. In press.

Wagner, J. R., H. Ali, R. Langlois, N. Brasseur and J. E. van Lier (1987) Biological activities of phthalocyanines-VI. Photooxidation of L-tryptophan by selectively sulfonated gallium phthalocyanines: $\sin$ glet oxygen yields and effect of aggregation. Photochem. Photobiol. 45, 587-594.

Weber, J. H. and D. H. Busch (1965) Complexes derived from strong field ligands. XIX. Magnetic properties of transition metal derivatives of $4,4^{\prime}, 4^{\prime \prime}, 4^{\prime \prime \prime}$-tetrasulfophthalocyanines. Inorg. Chem. 4, 469-471. 